\title{
EVALUASI PERKEMBANGAN WISATA BAHARI DI PULAU TIDUNG BESAR KEPULAUAN SERIBU
}

\author{
Evaluation of Marine Tourism Development at Tidung Besar Island, Seribu Islands \\ Silvyani Putri Sihotang, Bambang Sulardiono*) dan Frida Purwanti \\ Program Studi Manajemen Sumberdaya Perairan, Departemen Sumberdaya Akuatik \\ Fakultas Perikanan dan Ilmu Kelautan, Universitas Diponegoro \\ J1. Prof. Soedharto, SH, Tembalang, Semarang, Jawa Tengah - 50275, Telp/Fax. +6224 7474698 \\ Email: silvyani24@gmail.com
}

\begin{abstract}
ABSTRAK
Pulau Tidung Besar merupakan salah satu pulau di Kepulauan Seribu Provinsi DKI Jakarta yang menjadi destinasi wisata bahari. Perkembangan wisata bahari dapat memberikan dampak ekonomi, sosial-budaya dan lingkungan, sehingga perlu dilakukan evaluasi perkembangan wisata bahari. Tujuan penelitian ini untuk mengetahui perkembangan wisata bahari, dampak perkembangan wisata bahari dari aspek ekonomi, sosial-budaya dan lingkungan, dan mengevaluasi perkembangan wisata bahari menggunakan siklus wisata. Metode penelitian ini adalah metode deskriptif dengan analisis secara kualitatif. Data diperoleh dengan menyebar kuisioner kepada 98 masyarakat, 50 pengunjung dan 10 pengelola. Sejak tahun 2014 hingga 2016 terdapat penurunan pengunjung Pulau Tidung Besar yang disebabkan oleh tidak adanya penambahan daya tarik wisata dan belum maksimalnya perbaikan ataupun penambahan fasilitas pendukung. Dampak kegiatan wisata bahari di Pulau Tidung Besar untuk dampak ekonomi adalah penambahan lapangan kerja dan pendapatan penduduk, untuk dampak sosial-budaya terlihat dari kegiatan gotong royong penduduk dan dampak lingkungan adalah semakin meningkatnya kesadaran pemerintah maupun masyarakat terhadap keadaan terumbu karang, kebersihan lingkungan dan ketersediaan air bersih yang lebih baik.. Evaluasi perkembangan Pulau Tidung Besar masuk dalam tahap stagnasi menuju tahap penurunan/ peremajaan.
\end{abstract}

Kata Kunci: Evaluasi, Perkembangan, Dampak, Wisata Bahari, Pulau Tidung

\begin{abstract}
Tidung Besar island as part of the Seribu Islands is located at the Jakarta Province which become a marine tourism destination. Development of marine tourism could affect condition of economic, social-culture, and ecology, therefore need to be evaluate marine tourism development. The aims of the research are to know development of marine tourism, impact of marine tourism development based on economic, sosial-culture, ecology aspects and to evaluate development of marine tourism using tourist life cycle. The methods used in this research was descriptive method with qualitative analysis. Data obtained by distributed quistionnaires to 98 residents, 50 tourists and 10 staffs. Since the year 2014 to 2016, the visitors of Tidung Besar Island was decline due to lack of improvement or addition for supporting facilities. The marine tourism activities impact on economic aspect are increasing employment, the sosio-culture impact is lowering the "Gotong Royong" activities, and the ecological impact are good concern of the government and resident for coral reefs and better sanitation and availability of clean water. Evaluation of marine tourism development at the Tidung Besar Island is in the stagnation level toward decline/ rejuvenation.
\end{abstract}

Keywords : Evaluation, Development, Impact, Marine Tourism, Tidung Island

*) Penulis Penanggungjawab

\section{PENDAHULUAN}

Kepulauan Seribu yang berada di daerah DKI Jakarta merupakan suatu kepulauan, dimana terdapat banyak pulau didalamnya yang menjadi tujuan wisata. Kepulauan Seribu masuk ke dalam 10 destinasi pariwisata prioritas dalam Pembangunan Destinasi Pariwisata Prioritas Tahun 2016-2019 oleh Kementerian Pariwisata. Salah satu pulau yang berkembang ke arah pariwisata bahari adalah Pulau Tidung Besar. Perkembangan wisata Pulau Tidung Besar mengakibatkan beberapa perubahan, baik dari keadaan lingkungan maupun dari masyarakat. Selain itu perkembangan wisata juga mempengaruhi jumlah kunjungan wistawan dimana jumlah kunjungan ini berkaitan dengan daya tarik wisata yang ada di kawasan Pulau Tidung Besar dan tingkat kepuasan yang diperoleh wisatawan melalui daya tarik tersebut. Berdasarkan hal tersebut, maka diperlukan diadakannya evaluasi terhadap perkembangan wisata bahari di 
Pulau Tidung Besar menggunakan siklus hidup pariwisata sehingga nantinya dapat diketahui perkembangan wisata Pulau Tidung Besar menurut data yang diperoleh termasuk kedalam golongan Exploration, Involvement, Development, Decline, Consolidation, Stagnation, atau Rejuvenation.

Tujuan dari penelitian ini adalah untuk mengetahui (1) perkembangan wisata bahari di Pulau Tidung Besar, Kepulauan Seribu, (2) dampak perkembangan wisata di Pulau Tidung Besar baik dari segi ekonomi, sosial dan budaya, dan juga ekologi, (3) untuk mengevaluasi Perkembangan Wisata Bahari di Pulau Tidung Besar berdasarkan aksesbilitas, fasilitas, daya tarik wisata, dan kelembagaan di Pulau Tidung Besar.

\section{MATERI DAN METODE}

Materi

Materi yang digunakan dalam penelitian adalah objek daya tarik wisata yang menjadi potensi wisata, psikografis (lama waktu, minat, dan tujuan) wisatawan sebagai dampak perkembangan pariwisata bahari.

\section{Metode}

Metode penelitian yang digunakan adalah metode deskriptif dimana dilakukan pengumpulan data melalui kegiatan wawancara terhadap 98 responden masyarakat secara purposive sampling menggunakan rumus slovin (1960), 50 responden pengunjung secara accidental sampling dan 10 responden pengelola yang terdiri dari Dinas Pariwisata, Aparat Desa, dan Kelompok Masyarakat yang diambil secara purposive sampling, kemudian melakukan observasi. Data yang digunakan dalam penelitian ini terdiri dari data primer dan sekunder yang diolah baik secara kualitatif dan diinterpretasikan secara deskriptif dan akan dianalisis secara kualitatif.

Rumus Slovin (1960) dalam Juliana (2013), yaitu:

Keterangan : $\mathrm{n}$ : Jumlah Responden

$$
n=\frac{N}{1+(N x e 2)}
$$

N : Jumlah Populasi

e : Tingkat Kesalahan (10\%)

$$
\begin{aligned}
& \frac{5000}{1+(5000 \times 0,01)} \\
& =98 \text { Responden }
\end{aligned}
$$

\begin{tabular}{|c|c|c|c|c|}
\hline No & Unsur & Variabel & $\begin{array}{c}\text { Pengumpulan } \\
\text { Data }\end{array}$ & Analisis \\
\hline 1. & $\begin{array}{l}\text { Perkembangan } \\
\text { Wisata }\end{array}$ & $\begin{array}{ll}- & \text { Jumlah } \\
\text { - } & \text { Pengunjung } \\
\text { Jenis Atraksi } \\
\text { - } & \text { Wisata Bahari } \\
\text { Ketersediaan } \\
\text { Sarana dan } \\
\text { Prasarana } \\
\end{array}$ & $\begin{array}{l}\text { Survei } \\
\text { Survei } \\
\text { Survei \& } \\
\text { Observasi }\end{array}$ & $\begin{array}{l}\text { Deskriptif } \\
\text { Deskriptif } \\
\text { Deskriptif }\end{array}$ \\
\hline & Dampak Wisata & $\begin{array}{ll}\text { - } & \text { Dampak } \\
\text { Ekologi } \\
\text { - } & \text { Dampak } \\
& \text { Ekonomi } \\
\text { - } & \text { Dampak Sosial } \\
& \text { dan Budaya } \\
\end{array}$ & $\begin{array}{l}\text { Wawancara dan } \\
\text { Observasi } \\
\text { Wawancara dan } \\
\text { Observasi } \\
\text { Wawancara dan } \\
\text { Observasi }\end{array}$ & $\begin{array}{l}\text { Deskriptif } \\
\text { Deskriptif } \\
\text { Deskriptif }\end{array}$ \\
\hline
\end{tabular}

Tabel 1. Variabel Penelitian dan Metode Pengumpulan Data

\section{Analisis Data}

Analisis data dalam penelititian ini dilakukan secara deskriptif kualitatif, pendekatan kualitatif merupakan suatu prosedur penelitian dimana hasil dari penelitian tersebut adalah data deskriptif berupa kata-kata tertulis maupun lisan dari para responden sehingga menemukan kebenaran mengenai masalah penelitian (Apriyanti, 2014). Berdasarkan kuisioner yang diberikan kepada responden, maka diketahui informasi mengenai perkembangan wisata 
bahari, dampak dari kegiatan wisata bahari, sehingga evaluasi perkembangan wisata bahari dapat dilakukan, data-data yang diperoleh dianalisis, menggunakan siklus hidup pariwisata sehingga dapat diketahui perkembangan pariwisata.

\section{HASIL DAN PEMBAHASAN}

\section{Keadaan Umum Lokasi}

Kepulauan Seribu merupakan wilayah yang meliputi daratan dan lautan. Luas Kepulauan Seribu terentang dari pantai utara Jakarta hingga 100 mil laut kearah utara mencapai 11,81 Km2 (sumber dari BPS Kepulauan Seribu) dalam (Apriyanti, 2014).

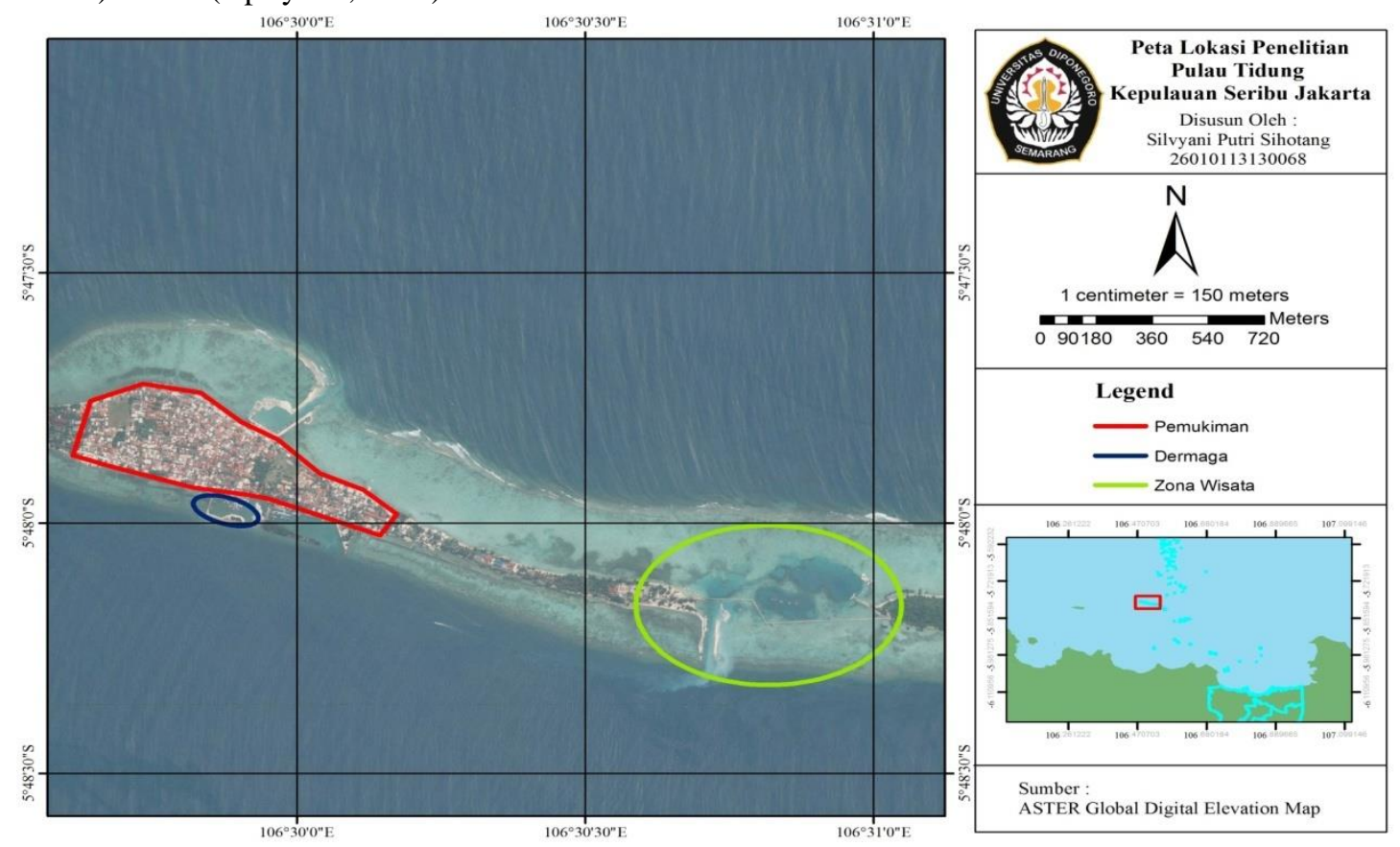

Gambar 1. Lokasi Pulau Tidung Besar, Kepulauan Seribu Sumber : Google Earth (2017)

\section{Profil Responden}

Profil Responden pada terbagi atas tiga golongan, yaitu masyarakat yang tinggal di Pulau Tidung Besar, wisatawan dan pengelola wisata bahari, dapat dilihat pada Tabel. 2

Tabel 2. Profil Responden Masyarakat, Wisatawan dan Pengelola Pulau Tidung Besar

\begin{tabular}{llll}
\hline Profil Responden & Masyarakat & Pengunjung & Pengelola \\
\hline Jenis Kelamin & & & 9 \\
- Laki-Laki & 43 & 16 & 1 \\
- Perempuan & 55 & 34 & 10 \\
\hline Jumlah & 98 & 50 & - \\
\hline Usia & & & - \\
- 16-20 & 0 & 13 & 1 \\
- 21-25 & 16 & 19 & - \\
- 26-30 & 10 & 9 & 4 \\
- 31-35 & 13 & 6 & 2 \\
- 36-40 & 22 & 2 & 3 \\
- 41-45 & 12 & 2 & 10 \\
- >45 & 25 & - & \\
\hline Jumlah & 98 & 50 & - \\
\hline Pendidikan & & & - \\
- SD & 23 & - & 4 \\
- SMP & 30 & - & 6 \\
- SMA & 41 & 36 & - \\
- S1 & 3 & 10 & - \\
- S2 & - & 1 & - \\
- S3 & - & - & 10 \\
- Lainnya & 1 & 3 & \\
\hline Jumlah & 98 & 50 & \\
\hline
\end{tabular}


Berdasarkan Tabel. 2 diketahui bahwa mayoritas responden masyarakat dan pengunjung adalah perempuan, sementara responden pengelola adalah laki-laki. Pada umumnya latar belakang pendidikan yang dimiliki oleh masyarakat dan pengunjung adalah SMA, sedangkan pengelola adalah Strata-1(Pegawai Sipil Negara seperti Kepala Kelurahan, Pegawai Suku Dinas,dan juga Anggota Kelembagaan). Kisaran usia pada responden masyarakat adalah $>45$ tahun, pada responden pengunjung 21-25 tahun, sedangkan pada pengelola 36-40 tahun.

\section{Psikografis Wisatawan}

Tabel 3. Psikografis Wisatawan Pulau Tidung Besar

\begin{tabular}{llll}
\hline Profil & Kategori Pengukuran & Jumlah (orang) & Persentase (\%) \\
\hline Sumber Informasi & Teman & 18 & 36 \\
& Internet & 29 & 58 \\
& Keluarga & 3 & 6 \\
& Sendiri & - & - \\
\hline Lama Waktu yang & $<1$ & - & 12 \\
Dihabiskan (Jam) & $1-2$ & 6 & 18 \\
& $3-4$ & 9 & 70 \\
\hline Tujuan Kunjungan & Berwisata & 35 & 100 \\
& Penelitian & 50 & \\
& Tugas & - & \\
\hline Frekuensi Kunjungan & 1 & - & 70 \\
(Kali) & 2 & - & 22 \\
& 3 & 35 & 8 \\
& $>4$ & 11 & - \\
\hline Jumlah Pengeluaran & $100.000-300.000$ & 4 & 18 \\
(Rp) & $301.000-500.000$ & - & 36 \\
& $501.000-700.000$ & 9 & 34 \\
& $701.000-900.000$ & 18 & - \\
& $901.000-1.100 .000$ & - & 10 \\
\hline
\end{tabular}

Berdasarkan olah data kuisioner yang tersaji dalam Tabel 3, terdapat beberapa pengukuran tentang psikografis wisatawan. Sebagian besar memperoleh informasi dari internet. Tujuan utama para wisatawan adalah berwisata, dengan rata -rata lama kunjungan > 4 jam. Umumnya pengunjung baru pertama kali datang ke Pulau Tidung Besar karena merasa penasaran dengan keadaan Pulau Tidung Besar, rata-rata uang yang dihabiskan untuk menikmati wisata bahari Pulau Tidung adalah Rp. 301.000 hingga Rp. 500.000,-.

\section{Kepuasan Wisatawan Berdasarkan Aksesbilitas dan Fasilitas}

Tabel 4. Keadaan Wisata Bahari Pulau Tidung Menurut Wisatawan

\begin{tabular}{lccccc}
\multicolumn{1}{c}{ Parameter } & $\begin{array}{c}\mathbf{1 - 3} \\
(\mathbf{s k})\end{array}$ & $\begin{array}{c}\mathbf{4 - 5} \\
(\mathbf{k})\end{array}$ & $\begin{array}{c}\mathbf{6 - 7} \\
(\mathbf{b})\end{array}$ & $\begin{array}{c}\mathbf{8 - 1 0} \\
(\mathbf{s b})\end{array}$ & Jumlah \\
\hline Aksesbilitas & 5 & 19 & 12 & 14 & 50 \\
Fasilitas & 0 & 27 & 16 & 7 & 50 \\
Keamanan & 0 & 0 & 17 & 34 & 50 \\
Kenyamanan & 0 & 0 & 10 & 40 & 50 \\
\hline Jumlah & $\mathbf{5}$ & $\mathbf{4 6}$ & $\mathbf{5 5}$ & $\mathbf{9 5}$ & $\mathbf{2 0 0}$ \\
\hline Persentase (\%) & $\mathbf{2}$ & $\mathbf{2 3}$ & $\mathbf{2 7}$ & $\mathbf{4 8}$ & $\mathbf{1 0 0}$ \\
\hline
\end{tabular}

Kepuasan wisatawan terhadap keadaaan wisata bahari dilihat berdasarkan aksesbilitas, fasilitas, kemanan dan kenyamanan (Tabel.4) menunjukkan $48 \%$ wisatawan merasa kondisi wisata sangat baik dimana faktor keamanan dan kenyamanan merupakan variabel tertinggi, meskipun demikian perlu dilakukannya perbaikan pada aksesbilitas dan juga fasilitas agar masyarakat bertambah puas dalam kegiatan wisata bahari.

\section{Penambahan Sarana dan Prasana}

Tabel. 5 dibawah akan menjelaskan mengenai penambahan sarana dan prasana meliputi penambahan jumlah transportasi laut, penginapan (homestay), kapal rekreasi atau diving, juga sarana sanitasi, sedangkan area untuk kegiatan wisata bahari tidak terdapat penambahan selama 3 tahun terakhir. 
Tabel 5. Penambahan Sarana dan Prasarana

Jenis Penambahan Sarana dan Prasarana Pendukung Kegiatan Wisata Bahari

Keterangan Kondisi ( Dalam 3 Tahun)

\begin{tabular}{ll}
\hline 1. Transportasi laut & Penambahan 5 Unit Kapal \\
2. Jumlah kapal rekreasi & Kapal dari nelayan \\
3. Jumlah penginapan & Dari masyarakat sendiri \\
4. Area kegiatan wisata bahari & Tidak ada penambahan \\
5. Sarana sanitasi & Penambahan petugas PSSU dan tong sampah \\
\hline
\end{tabular}

Perkembangan Wisata Bahari

Jumlah Kunjungan Wisata Bahari Pulau Tidung Besar

Tabel 6. Data Kunjungan Wisatawan Pulau Tidung Besar

\begin{tabular}{lcc}
\hline \multicolumn{1}{c}{ Tahun } & Jumlah & Persentase (\%) \\
\hline 2011 & 279.092 & - \\
2012 & 318.674 & +15 \\
2013 & 389.701 & +22 \\
2014 & 399.117 & +3 \\
2015 & 185.989 & -53 \\
2016 & 144.764 & -22 \\
\hline Jumlah & $\mathbf{7 2 9 . 8 7 0}$ & \\
\hline
\end{tabular}

Berdasarkan data jumlah kunjungan wisata bahari di Pulau Tidung Besar pada Tahun 2011-2016 dari Suku Dinas Pariwisata DKI Jakarta, didapatkan informasi bahwa pada tahun 2011 - 2014 terjadi kenaikan jumlah pengunjung, dimana pada tahun 2013-2014 masuk tahap stagnan dengan jumlah kenaikan hanya 2\%, kemudian terjadi penurunan drastis dari tahun 2014 ke tahun 2015 sebesar 53\%. Penurunan jumlah pengunjung yang terjadi di Pulau Tidung Besar menurut masyarakat setempat adalah karena tidak ada lagi penambahan fasilitas dan sarana-prasarana yang menunjang kegiatan wisata bahari seperti pada pulau-pulau lain,. Fluktuasi jumlah pengunjung dipengaruhi oleh beberapa faktor seperti pelayanan, sarana dan prasarana, obyek daya tarik wisata dan keamanan tempat wisata (Syahadat, 2005).

Daya Tarik Wisata Bahari

Tabel 7. Daya Tarik Wisata Pulau Tidung Besar

\begin{tabular}{|c|c|c|}
\hline Daya Tarik Wisata & Jumlah & Persentase (\%) \\
\hline Kondisi Alam & 43 & 43 \\
\hline Ciri Khas Masyarakatnya & 10 & 10 \\
\hline Ciri Khas Makanannya & - & - \\
\hline Fasilitas Penginapan & - & - \\
\hline Atraksi Wisata Pantai & 47 & 47 \\
\hline Jumlah & 10 & 10 \\
\hline
\end{tabular}

Daya tarik wisata pada umumnya ada pada kondisi alam dan atraksi wisata yang dimiliki Pulau Tidung Besar yang biasanya dinikmati para wisatawan di Jembatan Cinta. Atraksi wisata Pulau Tidung Besar dapat dilihat pada Tabel. 8 yang meliputi beberapa kegiatan, hal ini sejalan dengan pernyataan Razak dan Suprihardjo (2013) bahwa daya tarik wisata Pulau Tidung Besar terletak pada kegiatan menyelam ataupun snorkeling dan juga jembatan yang menghubungan Pulau Tidung Besar dan Tidung Kecil sambil menikmati pemandangan alam dan mengambil gambar. Penambahan daya tarik wisata pada Pulau Tidung Besar masih diperlukan agar tidak terkalahkan oleh pulau lainnya di Kepulauan Seribu, karena daya tarik wisata menjadi suatu hal yang mendorong kehadiran wisatawan mengunjungi kawasan wisata tertentu yang juga memperhatikan kelayakan daya tarik tersebut untuk berada di Pulau Tidung (Suwantoro, 2004).

Tabel 8. Atraksi Wisata Bahari Pulau Tidung Besar yang Paling Diminati Wisatawan

\begin{tabular}{ll}
\hline Atraksi Wisata & Durasi (Menit) \\
\hline Jembatan Cinta & $60-120$ \\
Menyelam & $45-60$ \\
Snorkling & $30-45$ \\
Banana Boat & 15 \\
Perahu Kano & $15-20$
\end{tabular}


Donut Boat 15

Speed Boat $15-25$

Jembatan Cinta yang menghubungkan Pulau Tidung Besar dan Pulau Tidung Kecil menjadi daya tarik wisata tersendiri bagi wisatawan untuk menikmati pemandangan alam dimana pada tabel diatas terlihat wisatawan paling lama menghabiskan waktu pada Jemmbatan Cinta, selain itu juga terdapat kegiatan olahraga air seperti yang dijelaskan pada Tabel. 8, dimana kegiatan yang paling diminati dari olahraga air adalah menyelam dan juga snorkeling. Daya tarik pada Pulau Tidung ini yaitu kegiatan berenang di pinggiran pantai, menyelam, dan juga snorkeling yang dipandu oleh masyarakat penyedia jasa setempat, sementara daya tarik lainnya adalah jembatan yang menghubungkan kawasan Pulau Tidung Besar dan Tidung Kecil dimana pengunjung biasanya menikmati pemandangan alam atau mengambil gambar di jembatan ini (Razak dan Suprihardjo, 2013).

\section{Ketersediaan Sarana dan Prasarana}

Sarana yang dimiliki oleh Pulau Tidung Besar meliputi Agen atau Biro Perjalanan yang biasanya digunakan oleh para wisatawan yang berasal dari suatu perusahaan ataupun sekolah, penginapan berupa homestay, penjualan karcis masuk maupun keluar dari Pulau Tidung, dan juga Transportasi darat maupun laut seperti Becak Motor dan Sepeda untuk transportasi darat, sedangkan kapal nelayan ataupun kapal penumpang yang disediakan untuk transportasi laut. Selain itu, masyarakat Pulau Tidung juga menyediakan Tour Guide yang biasanya dilakukan oleh para pemuda Pulau Tidung dan penyewaan alat seperti snorkel dan alat selam, dimana menurut Suwantoro (2014), sarana wisata adalah penyesuaian kelengkapan daerah dalam memenuhi kebutuhan para wisatawan untuk menikmati wisata tersebut.

Prasarana wisata merupakan suatu kebutuhan wisatawan dalam perjalanan wisata yang berhubungan dengan sumberdaya alam ataupun sumberdaya buatan manusia (Suwantoro, 2004). Prasarana di Pulau Tidung Besar cukup memadai seperti adanya ATM, Puskesmas juga melayani wisatawan, telepon umum, pelabuhan yang menjadi awal masuk pulau dan juga jalanan setapak. Prasarana tersebut sudah disediakan akan tetapi kondisinya harus diperbaiki ataupun diperbanyak, seperti halnya ATM di Pulau Tidung hanya terdapat 1 ATM di kelurahan, kemudian pelabuhan yang keadaannya harus diperbaiki melihat dinding tempat bersandar kapal sudah mulai retak dan juga secara fisik dermaga tersebut harus dibenahi agar memikat para wisatawan yang berkunjung, mengingat dermaga merupakan tempat pertama kali yang dilihat wisatawan setelah turun dari kapal penumpang.

\section{Dampak Perkembangan Wisata Bahari Pulau Tidung Besar}

Dampak perkembangan wisata bahari dapat dilihat dari dampak ekonomi, dampak sosial-budaya dan juga dampak lingkungan yang terkait dengan sarana-prasarana, aksesbilitas, jumlah kunjungan dan lain-lain.

\section{Dampak Ekonomi}

Tabel 9. Pekerjaan yang Berkaitan dengan Wisata

\begin{tabular}{llll}
\hline No. & Jenis Usaha & Jumlah & Persentase \\
\hline 1. & Pedagang Makanan & 19 & 19 \\
2. & Pedagang Baju & 3 & 3 \\
3. & Pedagang Souvenir & 1 & 1 \\
4. & Penyewaan Perahu & 9 & 9 \\
5. & Travel & 8 & 8 \\
6. & Penyewaan Snorkle & 6 & 6 \\
7. & Katering & 19 & 19 \\
8. & Tour Guide & 10 & 11 \\
9. & Homestay & 23 & 24 \\
\hline & Jumlah & $\mathbf{9 8}$ & $\mathbf{1 0 0}$ \\
\hline
\end{tabular}

Dampak ekonomi dari perkembangan wisata bahari dapat dilihat dari perubahan profesi pekerjaan pada masyarakat, dimana sebelum adanya kegiatan wisata bahari banyak masyarakat hanya menjadi nelayan kini berubah menjadi penyewa kapal untuk menyelam atupun penyewaan alat untuk snorkling maupun diving. Sejalan dengan pernyataan Ruswadi (2012) bahwa sejak dijadikannya Pulau Tidung sebagai daerah wisata bahari, sebagian masyarakat Pulau Tidung menjadi penyedia jasa kegiatan wisata dimana sebelumnya masyarakat bekerja sebagai nelayan. Kegiatan wisata bahari di Pulau Tidung sangat menambah lapangan pekerjaan bagi masyarakat dimana sekarang ini masyarakat memiliki usaha-usaha yang dominan berkaitan dengan kegiatan wisata bahari, penelitian Dritasto dan Anggraeni (2013) menunjukkan bahwa usaha yang dilakukan oleh masyarakat Pulau Tidung adalah $64 \%$ bidang jasa penginapan, $11 \%$ memiliki warung, $6 \%$ jasa catering, $5 \%$ usaha warung makan, $4 \%$ menyewakan alat, $3 \%$ sebagai pemandu wisata, $2 \%$ memiliki usaha transportasi kapal, dan $1 \%$ berjualan souvenir.

Pendapatan masyarakat setelah adanya perkembangan wisata bahari juga menjadi suatu dampak ekonomi, dimana grafik dibawah menyajikan data pendapatan yang diperoleh masyarakat melalui kegiatan wisata bahari di Pulau Tidung Besar, sehingga dapat diketahui bahwa dari 98 responden terdapat 63 masyarakat memperoleh pendapatan kurang dari Rp. 3.500.000, kemudian 31 masyarakat memperoleh pendapatan Rp. 3.500.000, sedangkan 4 masyarakat memperoleh pendapatan lebih dari Rp. 3.500.000. 


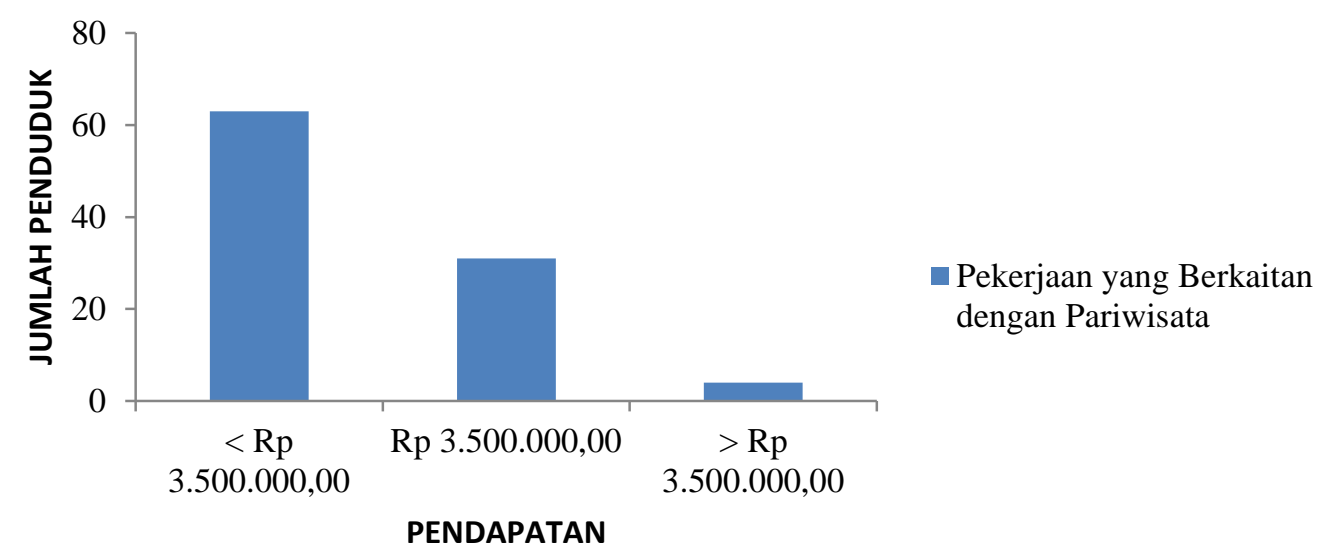

Gambar 2. Grafik Pendapatan Masyarakat Melalui Kegiatan Wisata Bahari

\section{Dampak Sosial-Budaya}

Kegiatan ekonomi yang dilakukan dalam wisata bahari, secara tidak langsung mempengaruhi pola kekeluargaan yang dimiliki oleh masyarakat, sebelumnya masyarakat Pulau Tidung Besar memiliki rasa kekeluargaan, tetapi setelah ada kegiatan wisata bahari muncul rasa iri ataupun persaingan ketat untuk mengambil keuntungan dalam kompetisi penawaran produk ataupun jasa yang disuguhkan kepada wisatawan. Menurut Oktaviyanti (2013) berkurangnya rasa tenggang rasa antar masyarakat ditandai oleh kompetisi menjual produk wisata terhadap wisatawan yang terkadang menjatuhkan antara satu dengan yang lain.

Pulau Tidung Besar merupakan suatu wilayah yang termasuk dalam pulau-pulau kecil yang mana pulau-pulau kecil biasanya memiliki suatu budaya, kearifan lokal ataupun kebiasaan-kebiasaan yang dilakukan penduduk setempat. Keterisolasian pulau-pulau kecil, menjadikan masyarakatnya mengadakan suatu kegiatan budaya setempat ataupun kearifan lokal (Razak dan Suprihardjo, 2013). Pengembangan wisata bahari di Pulau Tidung Besar menurut masyarakat setempat tidak mempengaruhi kearifan lokal seperti acara keagamaan bagi ibu rumah tangga setiap hari pukul 13.00 WIB walaupun masyarakat disibukkan dengan kegiatan pemenuhan kebutuhan para wisatawan terutama di akhir minggu atau weekend ataupun high season. Kehidupan bersosialisasi antar masyarakat Pulau Tidung Besar menurut mayoritas penduduk setempat setempat terdapat perubahan, seperti dalam hal kegiatan gotong royong dimana biasanya seluruh masyarakat ikut serta dalam hal tersebut.

\section{Dampak Lingkungan}

Tabel 10. Keadaan Lingkungan Menurut Masyarakat Pulau Tidung Besar

\begin{tabular}{lccccc}
\multicolumn{1}{c}{ Parameter } & Sk & K & B & Sb & Jumlah \\
\hline Keadaan Ekosistem & 0 & 4 & 23 & 71 & $\mathbf{9 8}$ \\
Ketersediaan Air Bersih & 0 & 0 & 21 & 77 & $\mathbf{9 8}$ \\
\hline Jumlah & $\mathbf{0}$ & $\mathbf{4}$ & $\mathbf{4 4}$ & $\mathbf{1 4 8}$ & $\mathbf{1 9 6}$ \\
\hline Persentase (\%) & $\mathbf{0}$ & $\mathbf{2}$ & $\mathbf{2 2}$ & $\mathbf{7 6}$ & $\mathbf{1 0 0}$ \\
\hline
\end{tabular}

Keterangan: Sk (Sangat Kurang) $=1-3 \quad$ B (Baik) $=6-7$

$$
\mathrm{K}(\text { Kurang })=4-5 \quad \mathrm{SB}(\text { Sangat Baik }=8-10
$$

Berdasarkan tabel diatas dapat diketahui bahwa keadaan ekosistem dan ketersediaan air bersih di Pulau Tidung Besar semakin baik karena semakin diperhatikan oleh pemerintah dan masyarakat juga semakin sadar dengan keadaan lingkungan sekitar mempengaruhi kehidupan sehari-hari masyarakat. Masyarakat setempat menganggap bahwa keadaan ekosistem sekitar Pulau Tidung dengan adanya kegiatan wisata bahari masih dikatakan baik karena masyarakat menjaga kondisi lingkungan Pulau Tidung untuk tetap melanjutkan kehidupan masyarakat yang tergantung akan keberadaan wisata bahari, Keberadaan wisata bahari di Pulau Tidung Besar, meningkatkan kesadaran masyarakat maupun pemerintah. Hal ini dapat dilihat dari kegiatan transplantasi karang di Pulau Tidung Besar, menurut Supriharyono (2016), hasil pengukuran tutupan karang di Pulau Tidung Besar dan sekitarnya ditemukan pada tahun 2015 relative lebih tinggi dibanding tahun 2005 yang disebabkan adanya pengelolaan terumbu karang melalui program Daerah Perlindungan Laut) melalui rehabilitasi karang maupun pengawasan daerah wisata..

Kebersihan Pulau Tidung Besar semakin diperhatikan dan ditingkatkan penanganannya seperti penambahan tempat sampah, adanya penampungan atau penimbunan sampah, dan juga penambahan cara dalam pengelolaan limbah sekitar Pulau Tidung Besar, Putra (2015) mengatakan bahwa permasalahan utama yang dimiliki Pulau Tidung Besar adalah masalah sampah yang juga sering diberitakan oleh media massa. Pada tahun 2016 pemerintah menyediakan tempat sampah lebih banyak, melakukan penanganan sampah dan limbah dengan lebih baik dan juga penambahan petugas kebersihan umum atau biasanya disebut dengan pasukan orange. 
Ketersediaan air bersih pada Pulau Tidung Besar dapat dikatakan baik, karena sebagian besar masyarakat Pulau Tidung Besar memperoleh air tawar dari sumur pribadi mereka, tetapi ada sebagian masyarakat yang tinggal dekat sekali dengan laut, mendapat air payau. Dengan adanya kegiatan wisata bahari yang membutuhkan air tawar lebih banyak, sekarang tersedia air RO ( Reverse Osmosis) untuk memenuhi kebutuhan masyarakat ataupun para wisatawan yang mana air ini digunakan untuk memasak ataupun kebutuhan air sehari-hari di homestay.

\section{Evaluasi Perkembangan Wisata Bahari di Pulau Tidung Besar}

Evaluasi perkembangan wisata bahari di Pulau Tidung Besar meliputi aksesbilitas menuju tempat wisata, fasilitas yang mendukung kegiatan wisata bahari, daya tarik wisata Pulau Tidung dan juga kelembagaan-kelembagaan ataupun pengelola daerah wisata bahari. Aksesbilitas di Pulau Tidung Besar menurut responden tergolong kurang memuaskan dan memadai karena kondisi kapal tradisional yang terkadang mengangkut penumpang melebihi kapasitas sehingga mengurangi kenyamanan diperjalanan, selain itu juga jam keberangkatan kapal yang hanya disediakan satu kali dalam sehari, kecuali hari minggu dilaksanakan 2 kali keberangkatan kearah Muara Angke. Hal yang menjadi faktor utama para pengunjung mengatakan fasilitas pendukung wisata bahari kurang adalah keadaan dermaga selayaknya diperbaiki agar menaikkan minat pengunjung di Pulau Tidung Besar dan juga ketersediaan ATM yang hanya 1 di Pulau Tidung. Menurut Modjanggo et al. (2015), fasilitas memiliki hubungan yang signifikan terhadap kepuasan para wisatawan yang nantinya berpengaruh terhadap kondisi jumlah pengunjung. Pengelola Pulau Tidung harus memperhatikan fasilitas-fasilitas yang ada di Pulau Tidung untuk mendukung kegiatan wisata bahari di kawasan Pulau Tidung, sehingga keadaan jumlah pengunjung tidak mengalami penurunan seperti tahun sebelumnya.

Menurut siklus hidup perkembangan pariwisata yang dilihat dari data jumlah pengunjung bahwa pada tahun 2011-2014 mengalami kenaikan dengan keadaan stagnan pada tahun 2013-2014, kemudian mengalami penurunan jumlah pengunjung pada tahun 2014-2016, Utama (2011) mengatakan bahwa tahap stagnasi merupakan tahap dimana angka kunjungan tertinggi telah tercapai dan berkurangnya daya tarik wisata daerah tersebut disbanding daerah wisata lain, yang kemudian setelah tahap stagnasi akan ada dua kemungkinan yang terjadi yaitu penurunan ataupun peremajaan dimana tempat wisata hanya ramai dikunjungi saat akhir pekan dan juga libur sekolah, untuk menghindari punah nya wisata ini diperlukan usaha-usaha keluar dari tahap stagnasi dengan melakukan peremajaan, maka dapat dikategorikan bahwa Pulau Tidung berada pada tahap stagnation menuju tahap penurunan atau peremajaan, sehingga diperlukan peremajaan segera agar tidak ditinggalkan oleh wisatawan yang nantinya berpengaruh terhadap kehidupan sehari-hari masyarakat lokal. Pulau Tidung perlu dikelola dengan baik dan juga dilakukannya penambahan maupun perbaikan fasilitas dan memperhatikan daya tarik wisata yang dapat dijual kepada wisatawan.

Perbaikan, penataan dan penambahan sarana dan prasarana yang mendukung kegiatan wisata bahari di Pulau Tidung menurut masyarakat dan wisatawan belum terlaksana dengan baik dimana seharusnya sesuai dengan Rencana Strategi (Renstra) Dinas Pariwisata dan Kebudayaan Provinsi DKI Jakarta Tahun 2013-2017 mengenai penataan, peningkatan dan perbaikan secara berkala terhadap sarana dan prasarana pariwisata. Daerah wisata yang telah masuk dalam tahap stagnan, perlu dilakukan penyiapan sarana dan prasarana untuk mendukung perkembangan wisata bahari (Hidayat, 2011).

\section{KESIMPULAN}

1. Perkembangan wisata bahari di Pulau Tidung diketahui mengalami penambahan jumlah pengunjung pada tahun 20111 hingga tahun 2014, stagnan pada tahun 2013-2014, kemudian mengalami penurunan pada tahun 2014-2016

2. Dampak perkembangan wisata bahari di Pulau Tidung Besar adalah dampak ekonomi yaitu penambahan lapangan kerja dan juga pendapatan penduduk, dampak sosial-budaya berpengaruh pada sosialisasi masyarakat dan dampak lingkungan yaitu kerusakan terumbu karang menurut masyarakat setempat dan juga peningkatan kesadaran masyarakat dalam kebersihan lingkungan.

3. Evaluasi perkembangan wisata bahari di Pulau Tidung Besar menggunakan siklus hidup berada pada tahap stagnasi menuju tahap penurunan/peremajaan.

\section{UCAPAN TERIMAKASIH}

Penulis sampaikan terimakasih kepada Prof. Dr. Ir. Supriharyono, MS yang telah memberikan masukan dalam penulisan artikel.

\section{DAFTAR PUSTAKA}

Apriyanti,R. 2014. Pengembangan Kawasan Wisata Air di Pulau Tidung Kepulauan Seribu. Universitas Gunadarma, Depok.

Dritasto,A, dan A.A. Anggraeni. 2013. Analisis Dampak Ekonomi Wisata Bahari Terhadap Pendapatan Masyarakat di Pulau Tidung. Institut Teknologi Nasional.

Hidayat, M. 2011. Strategi Perencanaan dan Pengembangan Objek Wisata (Studi Kasus Pantai Pangandaran Kabupaten Ciamis Jawa Barat). Politeknik Negeri Bandung, Bandung. 
Modjanggo, F., A. Sudhartono dan Sustri. 2015. Faktor-Faktor yang Mempengaruhi Jumlah Pengunjung ke Objek Ekowisata Pantai Siuri, Desa Toinasa Kecamatan Pamona Barat Kabupaten Poso. Universitas Tadulako, Palu.

Oktaviyanti,S.S. 2013. Dampak Sosial Budaya Interaksi Wisatawan dengan Masyarakat Lokal di Kawasan Sosrowijan. Universitas Gajah Mada, Yogyakarta.

Putra, F.A.E. 2015. Analisis Dampak Parowisata Terhadap Timbunan Sampah di Pulau Tidung. Universiitas Pembangunan Indonesia, Jakarta.

Razak, A. dan R. Suprihardjo. 2013. Pengembangan Kawasan Pariwisata Terpadu di Kepulauan Seribu. Jurusan Perencanaan Wilayah dan Kota, Fakultas Teknik Sipil dan Perencanaan Institut Teknologi Sepuluh Nopember (ITS), 2(1).

Resnawati, R. 2016. Strategi Community Practice dalam Pengembangan Pariwisata Berbasis Masyarakat. Universitas Indonesia, Depok.

Ruswadi, 2012. Studi Kerusakan Terumbu Karang di Perairan Pulau Tidung Kepulau Seribu DKI Jakarta. Universitas Indonesia, Depok.

Suku Dinas Pariwisata Kepulauan Seribu. 2017. Data Jumlah Kunjungan Pulau Tidung. Jakarta

Supriharyono. 2016. Kondisi Terumbu Karang di Pulau Tidung Kepulauan Seribu dan Sekitarnya. Universitas Diponegoro, Semarang. Jurnal Lingkungan dan Pembangunan. 2 (1); 332-346.

Suwantoro, G. 2004. Dasar-Dasar Pariwisata. Yogyakarta: Andi Offset.

Syahadat, E. 2006. Faktor-Faktor yang Mempengaruhi Kunjungan Wisatawan di Taman Nasional Gede Pangrango (TNGP). Universitas Nusa bangsa, Bogor.

Utama, I.G.B.R. 2011. Analisis Siklus Hidup Destinasi Pariwisata Bali: Kajian Ekonomi Pariwisata Terhadap Destinasi. 